\title{
Spatial Distribution of Resources and Poverty Incidence in Ghana
}

\author{
Isaac Akpemah Bathuure ${ }^{1}$, Lens Opoku Brobbey ${ }^{2} \&$ Kingsley Bawa ${ }^{3}$ \\ 1,2\&3 Jiangsu University, School of Finance and Economics, China \\ Correspondence: Isaac Akpemah Bathuure, Jiangsu University, China. E-mail: akpemah@gmail.com
}

Received: July 27, 2020; Accepted: November 15, 2020; Published: November 17, 2020

\begin{abstract}
This paper investigates the spatial distribution of resources, production activities and poverty in Ghana. The study found that the presence of natural resources in an area over a period of time greatly influences industrial activities in that locality. Moreover, given that firms or manufacturing industries will usually site their business ventures close to the sources of resource attraction, the processes of production including value addition, packaging, and refinery largely becomes vibrant in resource rich areas than less-resource zones. In Ghana, there seems to be an uneven distribution of natural resources across the administrative regions and ecological zones. This kind of distribution has resulted in the creation of additional jobs in areas endowed with natural resources. Data for the studies was obtain from Ghana statistical service

Spatial distribution of natural resources positively influences most important production activities in the discovered areas. A boom in production activities within an areas certainly reflect on the poverty incidence of the people since it creates both direct and indirect employment opportunities in that area. The paper suggests diversification of the economy, equitable allocation of resources to deprived areas to ensures comprehensive development and poverty alleviation in all aspects of life of the ordinary Ghanaian .Government needs to as well put in the needed measures to ensure people gets direct benefits from resources exploited in their communities as most of these exploitive activities pose negative externalities to the people.
\end{abstract}

Keywords: Ghana, spatial distribution, production activities, economic activities, poverty incidence

\section{Introduction}

Spatial or regional differences explain the unequal allocation of resources, wealth, and other development indicators across different localities or regions, with increasing significance among third world countries and global economies, including Ghana. It has become apparent that spatial and regional differences of wealth, productive activities, and other social indicators are on the increase (World Bank 2009). With a high dependence on our immediate environment combined with ever-growing environmental destruction due to Climatic and nonclimate causes, poverty continues to be a vitally important development issue in Ghana. (E.T. Lawson et al., 2012).

It has become a well-known phenomenon with a lot of empirical research backings which show that most developing countries that are highly endowed with natural resources tend to suffer slow economic growth and development due to various factors such as corruption, institutional framework, political instability, lack of necessary infrastructure among others.

All though natural resources might not have benefited some African and some developing countries, it's still an undeniable fact that they are major drivers and facilitators of growth and development. Areas with uninhabitable environments or limited natural resources are of higher tendency to fall into the poverty trap, and this is particularly true for most third world countries. With the desire to eliminate global poverty by 2030 , countries all over the world are implementing policies and making massive economic reforms with the sole aim of reducing this global hinder of sustainable development called poverty.

Gunn (2017) advocated for better understanding of poverty. He is of view that inability to have a clear understanding of poverty distribution may most likely prevent us from implementing appropriate socioeconomic interventions resulting in an inefficient allocation of resources, which aggravates the problem.

Studies carried out by reputable researchers have shown that poverty is not limited to low-wealth allocation but entails the absence of critical infrastructure in the form of education, healthcare, and housing. The dynamics of poverty has since been redefined from a single developmental concept to a multidimensional views (Wen et al., 2018). Adam and Mathias (2019), are also of the view that poverty is a multidimensional and socially embedded 
phenomenon with empirical evidence from economics, anthropology and sociology. Poverty is therefore not a simple lack of objectively identifiable resources but rather a complex combination of factors.

In Ghana, interregional differences, and intra-regional disparities, spatial differences have become significant drivers of social exclusion. Historically, the discussion over spatial inequality in Ghana hinges around the broad divide between the North and South, taking cognizance of natural resources availability. The Northern divide is found in the arid Savannah zone and shares borders with Burkina Faso. On the other hand, the coastal South encompasses the main export crop-growing areas and the three largest metropolitan areas (Lall, S. et al., 2009).

According to the UNDP HDR (2018), the supply of goods and services coupled with a harsh economic environment has positioned Northern Ghana more prone to exclusion experiences. Thus the uneven distribution of necessary infrastructure as well as remoteness from centers of trade all contribute to isolating some parts of the country. The differences in the provision of essential social services and job opportunities broadly reflect a wide range of social exclusion that is also influenced by rural-urban disparities

As indicated by the Ghana Living Survey (GLSS 6) report, among rural localities where poverty is prominent, the poverty incidence is much higher among those living in rural savannah. In 2012/13, the contribution to poverty incidence in rural savannah was found to be higher than in rural coastal and forest combined. Notably, rural savannah contributes more than $40 \%$ to Ghana's overall poverty (GSS, 2014). In actual sense, Ghana's coastal and forest zones seem to have found most of the country's critical natural resources compared to the savannah; thus, the principle of proximity to raw materials is applied when it comes to setting up of manufacturing firms. The South's districts are better connected to markets, making it possible to attract more firms, thereby increasing economic density within those areas. This opportunity resulted in creating job opportunities where essential resources such as gold, diamond, bauxite, oil, and cocoa are found, thereby reducing the incidence of income poverty in those districts. An individual's ability in a market economy like Ghana to consume goods and services depends on his or her income making the allocation, exploitation, management, and availability of all forms of resources a necessity.

However, the incidence of illegal mining activities popularly known as 'galamsey' in some mining areas remains an albatross around the necks of residence. Though 'galamsey' affects many facets of life, one place where its impact is being felt most is the pollution of rivers and water bodies which affects farming activities, the main occupation of most rural dwellers in Ghana. 'Galamsey' does not only pollute rivers and water bodies but also leaves death traps for residence and miners themselves (Bervely.L, 2018).

Numerous studies, both theoretical and empirical, have been conducted on the issues of poverty incidence and its alleviation, spatial distribution of resources, and other related areas.

Gao et al., (2020), in Lijiang's study in the mountainous villages of western china studying spatial differences and environmental causes determining poverty incidence and elimination using spatial statistical approaches and GeoDetector tools. The analysis confirmed a marked fall in poverty incidence in most Lijiang villages during 2014-2018 under China's poverty elimination strategy. However, there were distinct spatial differences for both poverty incidence and reduction. The leading environmental causes causing poverty incidence and reduction include lack of water storage and geological hazard risks. They recommended that tailor-made poverty alleviation focus on socioeconomic and ecological reasons influencing poverty incidence and reduction. Hoang Van et al (2019) in their work also discovered that families in forest areas in Vietnam were having higher income than those households in other rural non forest zones. This shows the importance of forest and other natural resources in the fight against poverty.

Notwithstanding, our study seeks to uncover whether or not production activities are boosted in areas where resources are found in commercial quantities and whether or not that has any bearing on poverty. Our emphasis will not be solely based on the divide of Northern and Southern Ghana in terms of the spatial distribution of resources. Still, it will also consider an intra-regional review of cases where specific districts within a region are natural resources-rich and juxtapose that to other districts to measure its impact on poverty. Among the 16 administrative areas in Ghana, the Western part is said to be the country's resource zone; hence we shall draw most inferences from that region. It is also worth noting that for the purpose of these studies the old ten regional demarcation of Ghana was used as there is no data available for the newly created six regions

\section{Spatial Distribution of Resources}

The recent discovery of oil in commercial quantities prompted Ghana's membership in the Extractive Industries Transparency Initiative (EITI) and the implementation of policies supporting natural resource sustainability in anticipation of achieving faster economic growth and development (Adams et al., 2018). Considering the inability 
of most African countries to efficiently and effectively maximize their natural resources use, Kopiński et al. (2013) is still optimistic about the fortunes of Ghana and came out with a conclusion that Ghana's oil discovery cannot be a curse, but at worst, a treatable disease.

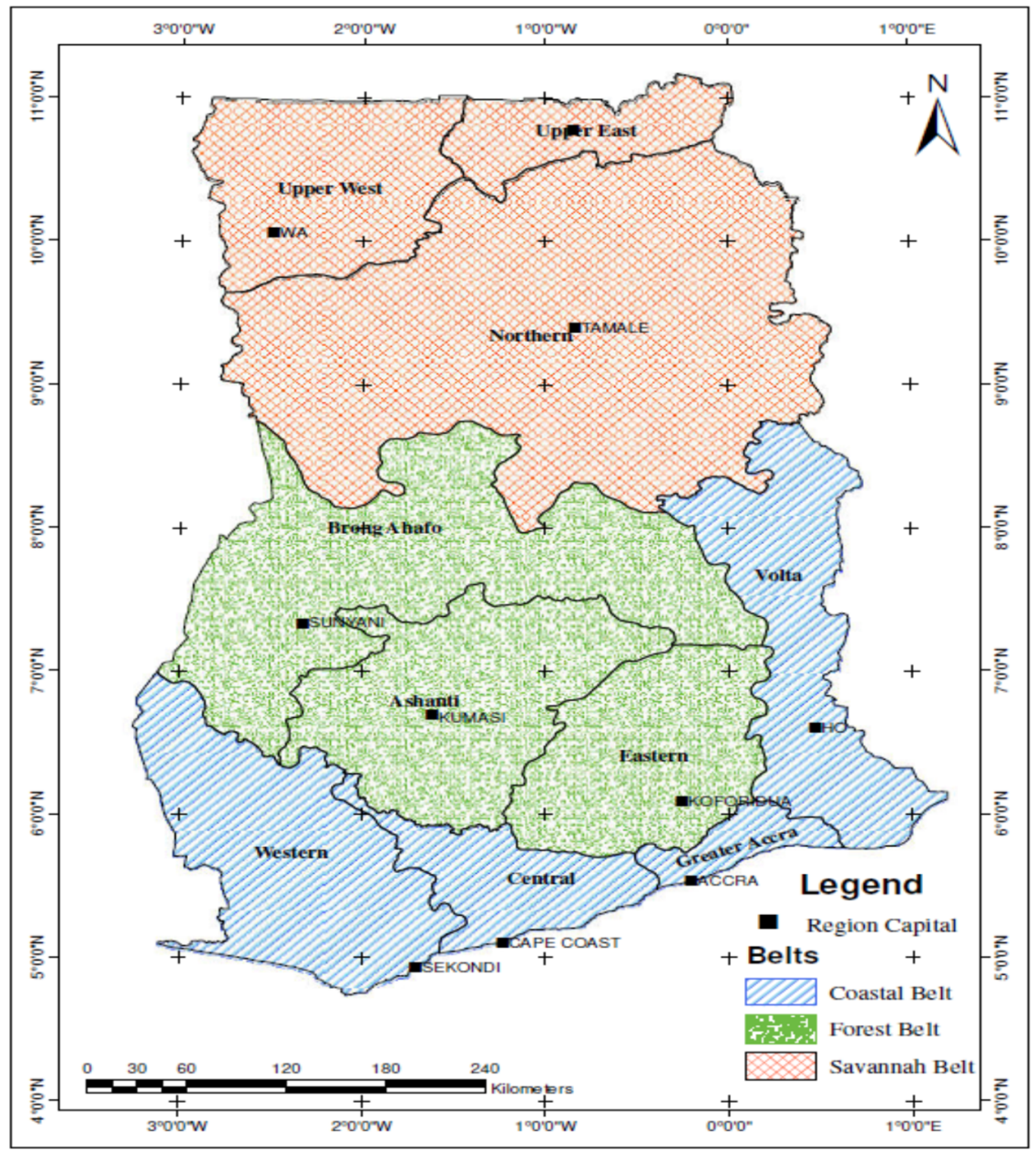

Figure 1. Regional distribution over the coastal, forest, and savannah belts of Ghana

Source: Department of Environment and Resource Studies (2013).

Ghana is divided into 16 administrative regions and categorized under three significant belts based on some common environmental characteristics, namely: Greater Accra, Central, Western and Volta Regions as the Coastal Belt; Ashanti, Brong-Ahafo and Eastern Regions as the Forest Belt; and Northern, Upper East, and Upper West Regions as the Savannah Belt (Ramsay \& Edge, 2004). However, these classifications are not absolute, as there are overlapping characteristics in some of the regions (Bukari F. et al., 2014). In Figure 1, the map of Ghana shows the distribution of the ten regions of Ghana and their major cities over the three belts of the country.

Most of the country's essential resources can be found in the coastal belt; however, some poverty and vulnerability incidents are still prevalent among the people who live in such areas. Despite the discovery of oil in the Western Region in 2010 and already existing natural resources, the region's severity of poverty had risen to $2.4 \%$ from $1.9 \%$ in 2013. In the coastal area, generally, poverty incidence also increased from $6.4 \%$ in 2006 to $9.9 \%$ in 2013 (GSS, 2015). This trend compels scholars to raise critical questions about whether the region's resources are a curse or a blessing and as to whether there is a direct benefit of these resources to the people who live within these resource rich zones.

\subsection{Minerals Production}

Ghana is endowed with several mineral deposits such as gold, Natural gas, diamond, silver, manganese, bauxite, iron ore, limestone, salt, and silica sands. The country has produced and exported gold for centuries. From precolonial times to the present-day, Ghana was one source of the gold that reached Europe through trans-Saharan 
trade routes, with the industry accounting for 5\% of the country's GDP and minerals make up 37\% of total exports, of which gold contributes over $90 \%$ (33.3\%) of the total mineral exports. Thus, the main focus of Ghana's mining and minerals development industry remains focused on gold. Ghana has also been a significant producer of bauxite, manganese, and diamonds in Africa

Therefore, it is instructive to note that the mineral basins are scattered all over the 16 administrative regions of Ghana. However, large deposits of minerals are found in the southern parts of Ghana. Again, most Gold mining companies and illegal mining activities commonly referred to as "galamsey" are located in the Western, Ashanti, and Central Regions. Diamond mining is frequently found in the Eastern region. The activities of "galamsey" have mainly led to water bodies' pollution that many dwellers in these areas depend on household consumption. This results in poor health, and an increase in social vices through local economies may boom.

Gold and bauxite alone account for $64.4 \%$ of Ghana's primary exports. The importance of this sector to Ghana's economy is on the increase. According to the Extractive Industries Transparency Initiative, an international body which monitors payments between governments and companies, Ghana's government took in $\$ 50$ million in mining revenues alone in 2011, compared to $\$ 20$ million in 2010

Despite the increase in revenue, it must be stated in general that the accurate picture of the sector is not exciting for the following reasons: (a) There has been limited transparency and public oversight responsibility regarding transactions, contracting, and decision making about mining projects. (b) Poorly designed fiscal terms, not benefiting the Ghanaian citizens. (c) The negative externalities, thus environmental and social effects, have not been given serious attention at the various stages of the mining projects, resulting damning consequences on the lives and livelihoods of people who live close to these projects. Mining activities primarily benefited the companies and helped little, if any, to the local communities and a few local elites, without any long-term improvements in the citizens' living conditions. (IEA, 2010).

\subsection{Oil and Gas Production}

The exploration of oil and gas in Ghana dates back to the 1890s in the Tano Basin. Following the discovering of oil and gas in larger quantities in 2007, the country began production after two years. Thus in 2010, Ghana started the commercial production of oil at the Jubilee Field located in the Western Region near Takoradi. With a forecasted production period of two decades, the field is estimated to produce between 800 million to over one billion barrels of oil and $120 \mathrm{mmscf} /$ day of associated gas (Alemzero et al., 2020). Ghana has already benefited a total sum of $\$ 4.009$ billion from petroleum revenue in the seven years of petroleum production. The current government flagship program on education, "Free SHS," is financed by oil resources income.

\subsection{Cocoa Production}

Cocoa came to Ghana in 1876 when a Ghanaian named Tetteh Quarshie brought some cocoa pods to Ghana from Equatorial Guinea. He cultivated the beans on his farm in Ghana and grew several seedlings, and from the 1900s, cocoa-growing spread in Ghana. By 1911, Ghana was the number one exporter of cocoa, feeding the European Chocolate market's increasing demand.

As introduced by commercial farmers in the Eastern Region's districts of Akuapem and Krobo and became the leading exporter of the world, Ghana saw a significant fall in productions in the 1960s-70s, with an almost fall of the sector in the early 1980s. Production steadily bounced back in the mid-1980s after the introduction of economic recovery programs. The 1990s brought about the revamping of the industry with output nearly doubling between 2001 and 2003.

Ghana's cocoa development could be identified in four different phases: the beginning and the fastest growth stage (1900 to 1937); stagnation followed by a brief but rapid growth following Ghana's independence (1938 to 1964); near collapse of the sector (1965 to 1982); and the recovery and expansion (1983 to 2008) with the beginning of the Economic Recovery Programme (Kolavalli \& Vigneri, 2008).

Cocoa production relies heavily on farmers and the availability of land, farmers' education, and the residents of the areas where cocoa is planted. These factors become the issues and barriers to poverty reduction and sustainable development (World Cocoa Foundation, 2012). According to the International Food Policy Research Institute, cocoa has played a significant role in Ghana's poverty reduction and development.

Ghana also plays an essential role in the international cocoa market. It is the second-largest cocoa beans producer globally after Ivory Coast and represents about $20 \%$ of global production (ICCO annual reports). Ghana's cocoa has grown by smallholder farmer Cocoa has been a significant contributor to Ghana's formal economy. Accounting for $30 \%$ of the total export ( $80 \%$ in raw form) earnings and provides about six million people. Anthonio and Aikins, (2009); Gockowski et al., 2011; USDA, (2012). Ghana's cocoa has grown by smallholder farmer engagement as 
the case of other cocoa-growing countries. The sector employs about 2 million people engaged in farming, trade, transportation, and cocoa processing (World Bank, 2011). Though the statistics look good, cocoa's real positive impact on people living within these regions cannot be directly felt because many people still do not have sufficient income to feed. Schools in most of these areas are still under trees, healthcare delivery is low, and unemployment is high.

\section{Methodology}

To analyze the spatial distribution of resources and poverty incidence in Ghana, the study used data from the Ghana statistical service (GSS) for 2005-2017. The study adapted and analyzed the data using Microsoft excel to show trends of poverty incidence through the distribution of natural resources. Deductions were made from data gotten from the GSS for the period 2005-2017, covering the various natural resources Ghana is endowed with. These provided the basis for the results that arrived obtained.

\section{The Relationship between Natural Resources, Production Activities, and Poverty}

Among the 16 administrative regions of Ghana, poverty and poverty gaps are not evenly distributed. Greater Accra, which is mainly driven by the services industry, has a shallow level (5.6\%) of poverty incidence, which is $18.6 \%$ points lower than the national poverty rate. The Upper West region had a high absolute poverty rate of $70.7 \%$ compared to the Western region's poverty rate of $20.9 \%$, which had more production activities within the districts than the Upper West region. The table below depicts the statistics;

The diagram below depicts a relationship between production Activities and Poverty in 2 regions

Table 1 . Poverty incidence and poverty gap by region

\begin{tabular}{llll}
\hline Regions & $2005 / 2006$ & $2012 / 2013$ & $2016 / 2017$ \\
Upper west & 89.1 & 70.7 & 70.9 \\
Western Region & 22.9 & 20.9 & 21.1 \\
national & 31.9 & 24.2 & 23.4 \\
\hline
\end{tabular}

Poverty incidence and poverty gap by region (\%), 2005/2006-2016/2017.Source: Authors'calculation

\section{Poverty Incidence and Gap by region}

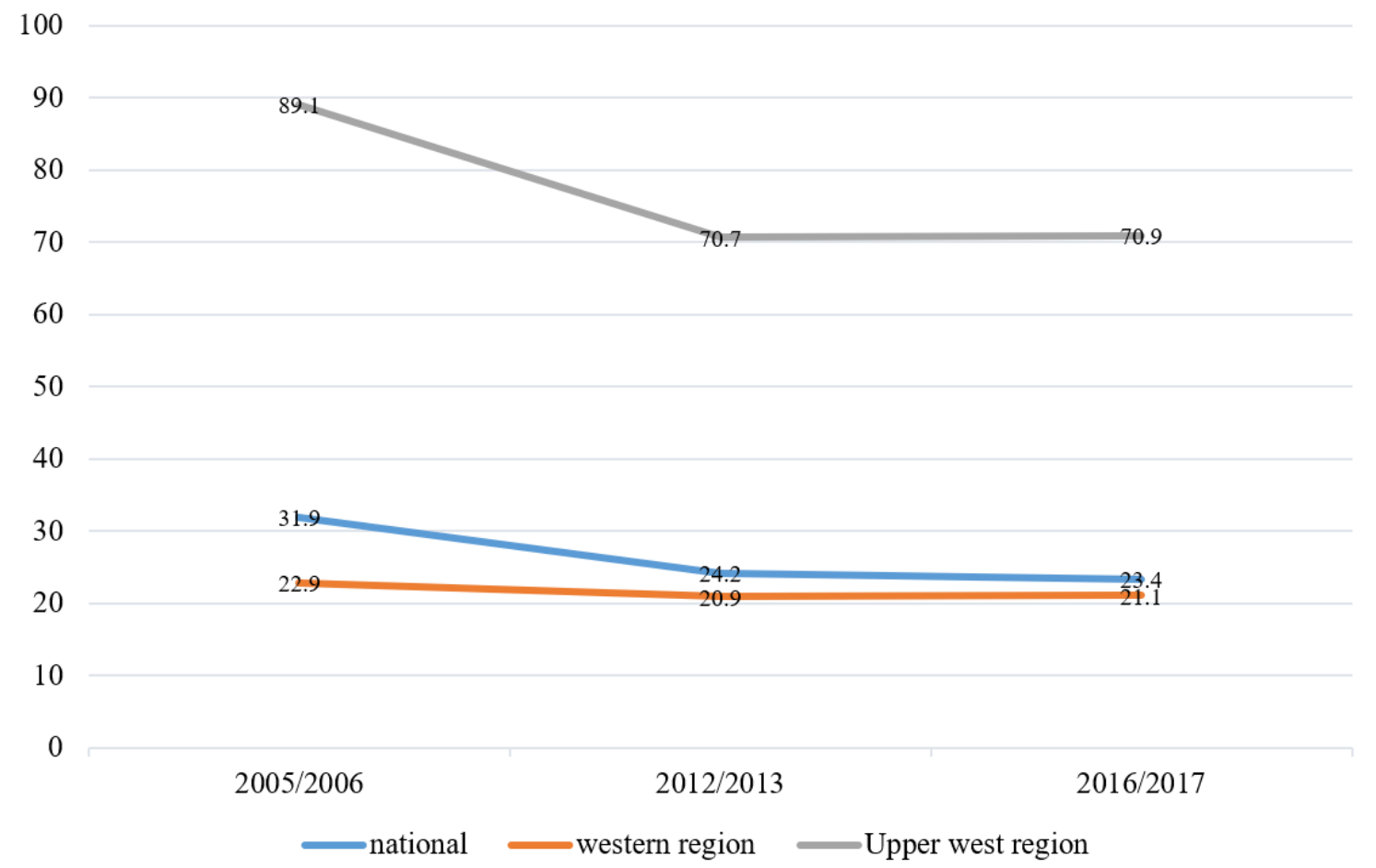

Figure 2. The relationship between production activities and poverty in Western and Upper West Region Source: GSS (2014) 
In the construction above, it is perceived that the significant resource-rich region (Western) records a low incidence of poverty $(20.9 \%)$ that is below the national average of $24.2 \%$. The global trend also shows that oil and gas are other essential commodities contributing too many economies, including Ghana. The discovery of these resources mostly attracts manufacturing firms and industries to be located close to such areas, thus creating employment opportunities and invariably contributing to poverty reduction. However, gold mining in the Upper West region is still on a small scale; therefore, it cannot absorb most of the unemployed workforce. The shea industry is growing at a fast pace. Exports have increased by $600 \%$ in the last 20 years. Over the previous three years, partnerships between the private sector, donors, civil society organizations, and government committed US\$ 37 million to empower women and protect the ecosystem in shea producing communities (Global Shea Alliance, 2019). However, the real picture is that the industry is only benefitting aggregators over local producers. Though employing many women, the rate of poverty reduction has not been significantly felt due to the industry's expansion. Stakeholders should, therefore, design policies that protect the interest producers in shea processing communities for poverty to decline.

\subsection{The Western Region of Ghana}

From the earlier discussion, it has been revealed that the Western Region has the largest deposit of natural resources in the country, and it is considered a case for our study.

The figures below depict the poverty index and spatial distribution of mineral resources in the Western region of Ghana.

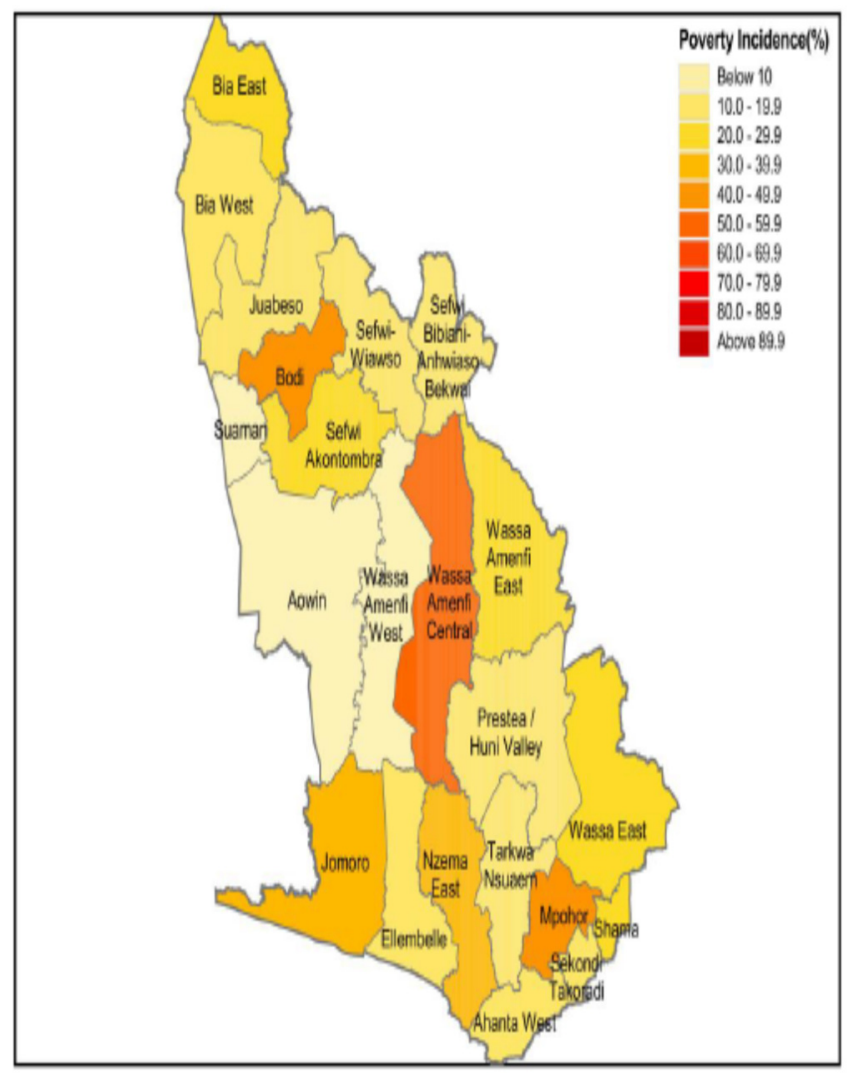

Figure 3. Poverty Map of the Western Region Source: GSS, 2015 


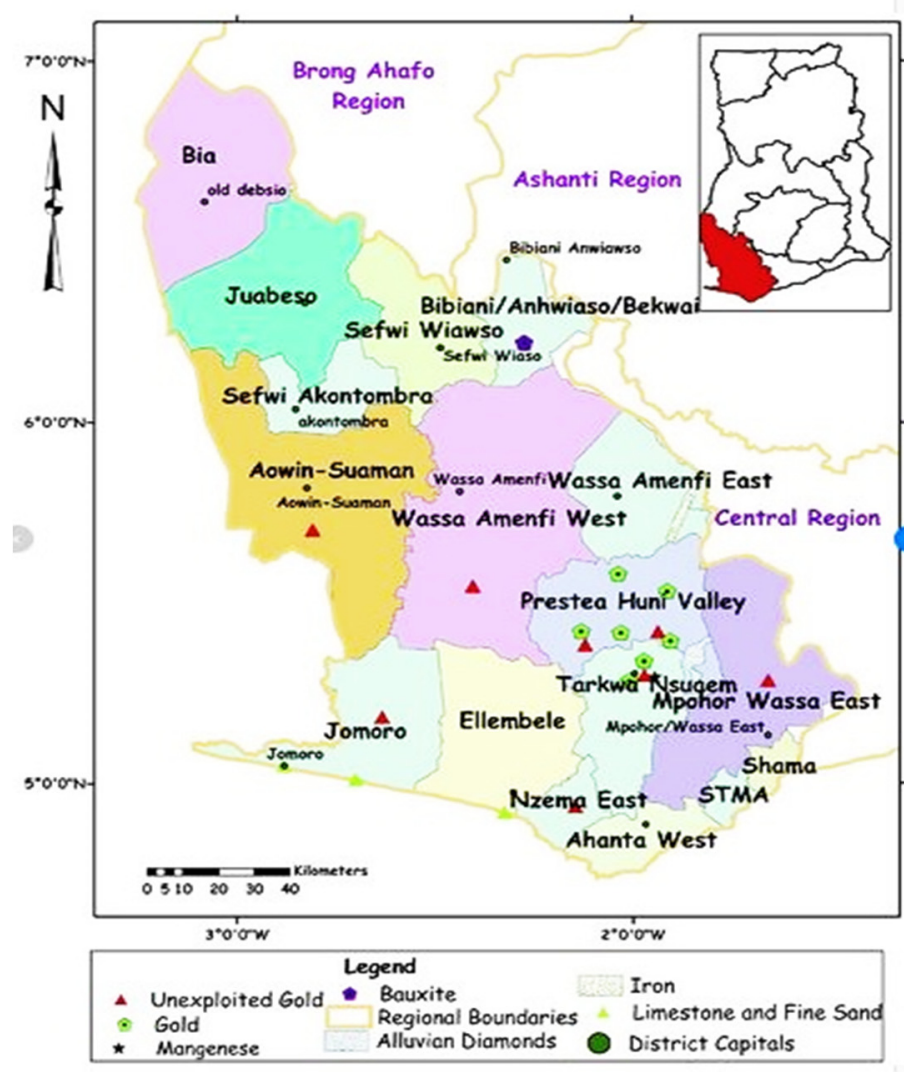

Figure 4. Resource Map of the Western Region

Source: minerals commission Ghana.

A cursory look at maps above shows that Aowni, Wassa Amenfi West, and Suaman mainly engage in cocoa production resulting in a less than $10 \%$ poverty incidence, which is lower than the regional average of $20.9 \%$ and $24.2 \%$ as the national average.

Also, Prestea and Tarkwa have a large deposit of Gold and mining activities in different areas, which have attracted many economic activities and employment opportunities, causing poverty, which stands at $15 \%$, to fall below the regional and national averages as stated above.

Wassa Amenfi Central records a poverty incidence rate of 60-69.9\%, higher than the regional and national averages. This district has five (5) forest reserves, limited cocoa production activities, hence limited employment opportunities.

Notwithstanding this, economic activities are centered on agriculture that employs about $77.4 \%$ of the population (GSS, 2014). Still, due to the large forest reserves, these agricultural activities are high on the subsistence level.

Countries with a lot of natural capital are considered lucky and can use these resources to turn around their economies' economic development. However, this wealth usually ends up with dismal economic growth and development. This situation is known as the resource curse. It explains these countries have not developed well considering the resources at their disposal but rather retrogressed in their economic development path. This explains the negative impact of these natural resources on these countries. (Kurečić and Seba, 2016)(Alemzero et al., 2020)

\section{Conclusion}

This paper investigates the spatial distribution of resources, production activities, and poverty in Ghana. In the study, the presence of natural resources in an area dramatically influences industrial actions in that locality. Moreover, given that firms or manufacturing industries will usually site their business ventures close to resource attraction sources, production processes, including value addition, packaging, and refinery, mostly become vibrant than less-resourced zones. There seems to be an uneven distribution of natural resources across the administrative 
regions and ecological zones in Ghana. This kind of distribution has resulted in the creation of additional jobs in areas they are found as well as increasing poverty incidence in areas with few resources.

It is observed that poverty may be prevalent in areas where resources are mostly exploited at the expense of the people who live there. Furthermore, economic activities usually are promoted within such geographical areas, which affect the level of inflation within the local economy. The cost of living becomes so high for the locals and ordinary residents, which, to a small extent, increases the poverty incidence of the people this can true for some mining communities in Ghana. Notwithstanding this argument, the shortage of natural resources in an area is said to still have a broader effect on poverty incidence as in the case of the Upper West region; hence, efforts must be directed at prospecting and exploiting the unexploited resources in various location of Ghana that could aid in bridging the developmental gap of the country.

The spatial distribution of natural resources positively influences the most crucial production activities in the discovered areas. A boom in production activities within an area certainly reflects the people's poverty incidence since it creates direct and indirect employment opportunities in that area. Ironically, Greater Accra is said to be among the fewer resources regions in the country; however, production activities are still high because resources are conveyed to Accra and Tema for production, creating more economic opportunities and reducing poverty incidence (5.6\%) (GSS, 2014).

Beyond the development gap between the southern half and northern half of the country, it is also a noticeable fact that most of the disparities exist between resources exploited areas and non-resource used areas.

For Ghana to bridge the spatial inequalities that exist in the country, there must be a strong commitment by the government to ensure that the following are met: The government should plan for better rural-urban linkages, improved regulation in the mining sector to regulate illegal mining.

Ensuring that people have equitable access to basic needs and public goods. Decentralization of Ghana's industrial sector to ensure equal development, Diversification of the economy should be vigorously pursued, Royalties must be dedicated to the development of infrastructure in the localities, and In order to create direct jobs or employment, processing plants should be sited in the localities

\section{References}

Alemzero, D. A. et al. (2020). 'Assessing the perceived impact of exploration and production of hydrocarbons on households perspective of environmental regulation in Ghana', Environmental Science and Pollution Research. Environmental Science and Pollution Research. https://doi.org/10.1007/s11356-020-10880-3

Wen, Q., Shi, L., Ma, C., \& Wang, Y. (2018). Spatial heterogeneity of multidimensional poverty at the village level: Loess Plateau. Acta Geogr. Sin. 73, 1850-1864. [Google Scholar]

Hoang Van, Cuong Van and Tran Quang, Tuyen and Nguyen Thi, Yen and LAN Nguyen, Thanh (2019). A propensity score matching analysis of the relationship between forest resources and household welfare in Vietnam.

Adam, M., \& Matias, P. (2019). Poverty Alleviation as an Economic Problem. Cambridge Journal of Economics, Oxford University Press, 43(1), 205-221. https://doi.org/10.1093/cje/bey010

Gao, P., Liu, S., Qi, W., \& Qi, H. (2020). The Nexus between Poverty and the Environment: A Case Study of Lijiang, China. Sustainability, 12, 1066. https://doi.org/10.3390/su12031066

Gunn, D. (2017, Jan. 26). Why poverty is skyrocketing in the suburbs. Pacific standard.

Adams, D. (2018). Resources Policy. https://doi.org/10.1016/j.resourpol.2018.03.005

Kopiński, D., Polus, A., \& Tycholiz, W. (2013). Resource curse or resource disease? Oil in Ghana. Afr. Aff., 112, 583-601. https://doi.org/10.1093/afraf/adt056

African Economic Outlook Report. (2015 \& 2016).

Anthonio, D. C., \& Aikins, E. D. (2009). Reforming Ghana's cocoa sector - an evaluation of private participation in marketing. Master Thesis. The Luleå University of Technology Master.

Bervely, L. (2018). Fighting' Galamsey' and River Pollution in Ghana; assessed from http://ghana.gov.gh/index.php/media-center/features/3187-fighting-galamsey-and-river-pollution-in-ghana

Gill \& Duffus Group. Cocoa Statistics, various issues

Ghana Statistical Service. (2015). Ghana Poverty Mapping Report.

Gockowski, J., Afari-Sefa, V., Sarpong, D. B., Osei-Asare, Y. B., \& Dziwornu, A. K. (2011). Increasing income of 
Ghanaian cocoa farmers: Is introduction of fine flavor cocoa a viable alternative. Quarterly Journal of International Agriculture.

Ghana Country notes for the African Economic Outlook (AEO, 2015 and 2016) for analysis.

Global Shea Alliance Secretariat (2019). Shea, 2019.

International Cocoa Organization. (2004). International Cocoa Organization annual report 2001/2002. ICCO Annual Report 2001/2002. http://doi.org/10.1108/eb055690

Jebuni, C. (2006). "Development in the North," presentation to the ISSER conference on Economic Development and Northern Ghana, 11-14 September 2006, Bolgatanga and Tamale, Ghana. Retrieved from http://www.saga.cornell.edu/saga/gh0906/ghana0906.html

Land Use and Spatial Planning Authority (LUSPA, previously Town and Country Planning Department, TCPD) (2015a). Spatial Development Framework for the Northern Savannah Ecological Zone (2015-2035) Volume I: Situational Analysis and Major Issues.

McLaughlin, J. L., \& Owusu-Ansah, D. (1994). The Colonial Era: British Rule of the Gold Coast. Washington: Federal Research Division, Library of Congress.

Shashi, K., \& Marcella, V. (2008). Cocoa In Ghana: Shaping The Success Of An Economy.

The Ghana Poverty and Inequality Report (2016).

UNICEF Ghana. (2013) "Advocating for Development that leaves no Child Behind".

USDA. (2012). Global Agricultural Information Network (GAIN) Report. Accra.

World Bank (2011). Supply Chain Risk Assessment: Cocoa in Ghana. Ghana Cocoa SCRA Report.

WanaGopa - Nyawakan Miller, G.T. \& S. Spoolman (2011). Living in the Environment Principles, Connections, and Solutions $\left(17^{\text {th }}\right.$ ed. $)$

\section{Copyrights}

Copyright for this article is retained by the author(s), with first publication rights granted to the journal.

This is an open-access article distributed under the terms and conditions of the Creative Commons Attribution license (http://creativecommons.org/licenses/by/4.0/). 